\title{
The importance of the use phase on the LCA of environmentally friendly solutions for asphalt road pavements
}

\author{
João Paulo C. Araújo \\ Department of Civil Engineering, University of Minho, 4800-058 Guimarães, Portugal \\ Tel. +351253510 200; Fax: +351253510217 \\ E-mail: jparaujo@civil.uminho.pt \\ Joel R.M. Oliveira (corresponding author) \\ C-TAC, Department of Civil Engineering, University of Minho, 4800-058 Guimarães, \\ Portugal \\ Tel. +351 253510 200; Fax: +351253 510217 \\ E-mail: joliveira@civil.uminho.pt
}

\section{Hugo M.R.D. Silva}

C-TAC, Department of Civil Engineering, University of Minho, 4800-058 Guimarães, Portugal

Tel. +351 253510 200; Fax: +351253510217

E-mail: hugo@civil.uminho.pt

\begin{abstract}
In order to assess sustainability of products and processes, different methodologies have been developed and used in the last years. In the road pavement construction area, most methodologies used for life cycle assessment (LCA) are essentially focused
\end{abstract}


in the construction phase. The present paper analyses the importance of the use phase of a road in the LCA of different paving alternatives, namely by evaluating energy consumption and gaseous emissions throughout the road pavement's life. Therefore, a new LCA methodology for road pavements was developed, and the results of its application to a case study involving the construction of alternative pavement structures are discussed. The study intends to assess the influence of using more sustainable paving construction alternatives (asphalt recycling vs. conventional asphalt mixtures), and/or different surface course materials (which have a higher influence on the rolling resistance and, therefore, affect the performance during the use phase). The LCA results obtained for this case study showed that the reductions in energy consumption and gaseous emissions obtained during the use phase, for pavement alternatives with a lower rolling resistance surface course, are higher than the total amount of energy consumption and gas emissions produced during construction. It is therefore clear that some improvements in the characteristics of the surface course may have an effect over the road use phase that will rapidly balance the initial costs and gas emissions of those interventions. The LCA results obtained also showed that the sustainability of pavement construction may also be improved using recycled asphalt mixtures.

\section{Keywords}

Life cycle assessment (LCA)

Road pavements

Use phase

Rolling resistance

Energy consumption 


\section{Introduction}

Presently, road pavements are infrastructures of great importance for the economic development of any Country, which led to significant investments being made in their construction. However, if in the past the main criterion used in the design of such infrastructures was to build them at the lowest cost, provided that structural capacity and safety were assured, currently there are other concerns on this matter, valuing the environmental perspective and seeking to determine all long term impacts (economic, social, environmental, or other) of this type of investments.

The concept of sustainable development has been subjected to various interpretations. One of the main definitions, and probably the one that has been best accepted by society appeared in 1987 in the document "Our Common Future" (WCED, 1987), commonly known as the "Brundtland Report", which defined it as the development that "meets the needs of the present without compromising the ability of future generations to meet their own needs".

Initially, the environmental dimension of this process was limited to immediate and highly visible phenomena, but with time the importance of factors such as energy consumption or the greenhouse gases emitted to the atmosphere became significantly higher. Currently, the term "sustainability" is broadly applied to almost every facet of life, although it is being increasingly used in the context of human sustainability on Earth, with special focus on the causes of global warming and climate change (Wathne, 2010).

In its essence, sustainable development implies a balance between economic and social development and environmental protection, i.e., between human activities and the natural world. Thus, as the perception of the world's limited resources (minerals, 
fossil fuels, etc.) increases, searches for solutions to reduce their dependence are intensified.

Any construction activity, namely that of constructing road pavements, has a significant impact on the environment. A direct impact results from the activity inherent in the construction, due to the consumption of energy and natural resources as well as the release of gaseous emissions to the atmosphere. However, its effects on the environment continue during the infrastructure use phase, increasing during periods that involve maintenance, renovation and demolition operations.

In this context, different Life Cycle Assessment (LCA) methodologies of road pavements have been developed in the last years. The fundamental objective of any LCA methodology is to evaluate a product or service throughout its life, considering the direct and indirect impacts. A thorough quantification of environmental impacts of pavements requires information from numerous sources related to stages of its life cycle, even tough, these are not always available (Noshadravan et al., 2013). Although the concept seems simple, its application becomes more complicated due to the lack of understanding of the system under study and the difficulty of obtaining relevant data, which leads to a rather limited vision of the life cycle. In the case of road pavements, only the activities of extraction, production, transportation and application of materials are usually considered (Santero et al., 2011b).

However, depending on the traffic volume, the energy consumption of the traffic during the lifetime of a road it is about of 95 to $98 \%$ of the total energy consumption, while the energy used for construction, maintenance and operating the road represents less than 2 to $5 \%$ of the energy used (EAPA/Eurobitume, 2004). According to Pérez-Martínez (2012) road transport is one of the largest sources of emissions within the economical sectors, accounting for up to $30 \%$ of the total energy consumption and $\mathrm{CO}_{2}$ emissions. 
Taking the abovementioned into consideration, this paper analyses the importance of the use phase of a road in the energy consumption and greenhouse gas emissions throughout its life. In order to achieve that goal, it was necessary to develop a new methodology to analyze the life cycle of road pavements, which is also described in the paper, and the results of its application to a case study involving the construction of different pavement structures are also discussed. The case study intends to assess the influence of using more sustainable paving alternatives, like asphalt recycled materials, in comparison with conventional asphalt mixtures, which is expected to have a higher effect during the construction phase, and the use of different surface course materials, which may have a higher influence on the rolling resistance of the vehicles and, therefore, affect the performance of the pavement during the use phase. The influence of each of those phases (construction and use) is also analyzed to determine their relative importance in the LCA.

\section{Literature review}

In addition to the definition of sustainable development given above, from the Brundtland report, other definitions could be highlighted. For example, in 1991, the International Union for Conservation of Nature has defined sustainable development as that "improving the quality of human life while living within the carrying capacity of supporting ecosystems" (CIB, 1999). In 1996, the American Society of Civil Engineers has defined it as "the challenge of meeting human needs for natural resources, industrial products, energy, food, transportation, shelter, and effective waste management while conserving and protecting environmental quality and the natural resource base essential for future development" (ASCE, 2008). 
As a way to address these concerns, several methodologies for Life Cycle Assessment (LCA) have been proposed, which primary goal is to evaluate a product or service throughout its life, considering the direct and indirect impacts.

The ISO 14040 (2006) Standard divides the process of Life Cycle Assessment in 4 phases: (1) The goal and scope definition; (2) Inventory analysis; (3) Impact assessment; (4) Interpretation. After the definition of the aim and scope of the study that "shall be clearly defined and shall be consistent with the intended application" (ISO $14044,2006)$, the main work is the development of an inventory in which all significant environmental burdens during the lifetime of the product or process are collected and quantified, followed by an assessment of impacts that are presented in order to allow its comparison or further analysis (Huang et al., 2009a). The Life Cycle Inventory (LCI) includes different sub-steps such as raw materials extraction, transportation, production, consumption and waste disposal (Stripple, 2001).

The impact assessment phase, defined as a technical process, quantitative and/or qualitative, to characterize and evaluate the effects of the flows identified in the previous phase, consists of the systematic evaluation of impacts, namely the determination of the potential contribution of the product for the categories of environmental impact, such as global warming, acidification, among others (Bragança and Mateus, 2012).

The life cycle of a pavement is divided into five phases: (1) raw materials and production, (2) construction, (3) use, (4) maintenance, (5) end of life (Santero et al., 2011b). According to these authors, each phase comprises various components, each representing a unique interaction between the pavement and the environment. These authors analyzed and compared 15 methodologies for Life Cycle Assessment of road 
pavements and found out that even though there are a few studies that seek to include the use phase in the assessment, their analyses are considerably incomplete.

The majority of LCA methodologies ignore the road use phase, neglecting the enormous supremacy of this phase with respect to energy consumption and gaseous emissions released during the life cycle of the road. These are in fact two of the main aspects to be taken into account in the analysis of the life cycle, although, other factors are mentioned in the literature regarding life cycle assessments of road pavements, especially during the use phase. The most significant factors that can be highlighted are: the energy used for lighting the road, the carbonation of concrete that occurs in rigid pavements, the albedo, the leachate production and the rolling resistance.

Material type and age of the pavement influence the reflectivity of light. Thus, the illumination required to ensure the same visual conditions will be different for each type of pavement. Adrian and Jobanputra (2005) have concluded that flexible pavements require 57\% more energy expenditure than concrete pavements for an adequate lighting. However, the difference in reflectance is lower in aged pavements, because the asphalt tends to lighten with time, while the concrete pavements tend to darken (Santero et al., 2011a).

Carbonation of concrete in rigid pavements corresponds to carbon capture by the concrete, which can partially offset the $\mathrm{CO}_{2}$ that was released during cement production. This is a very slow process, with the $\mathrm{CO}_{2}$ absorption rate dependent of aspects such as the porosity of concrete, cement content, water cement ratio and the temperature and relative humidity of the surrounding environment (Engelsen et al., 2005; Gajda, 2001; Lagerblad, 2006). However, this issue was not considered in the present work, since only asphalt materials have been studied. 
According to Noshadravan et al. (2013), the albedo is a measure of the ability of the pavement surface to reflect the incoming solar radiation, which can vary from 0 (for total absorption) to 1 (for the total reflectance). The expected albedo values for asphalt pavements is between 0.05 and 0.20 , while for concrete pavements it will vary between 0.25 and 0.40 . There are however some factors, such as age and type of pavement surface, influencing its albedo. In the case of asphalt pavements the albedo tends to increase with age, since they tend to become clearer, in contrast with the concrete pavements for which the albedo tends to decrease due to the darkening of the surface (Wathne, 2010).

The study of leachate from road pavements is a theme that has raised some interest to some researchers, since some paving materials contain substances that pose a threat to drinking water and aqueous ecosystems during the pavement's life cycle. Nevertheless, most of the published studies show a small risk of leaching of contaminants in dangerous concentrations in storm water runoff (Brandt and De Groot, 2001; Marion et al., 2005).

Rolling resistance is the energy loss due to the interaction of the vehicle with the pavement. There are many factors influencing the rolling resistance, which can be related to the tires, the environment and the pavements (Woodside et al., 2003). Regard the pavement characteristics, rolling resistance can be influenced by the material stiffness and by the surface characteristics. According to Heywood (1988) a portion of the useful power of a vehicle is used to overcome rolling resistance. Accordingly, it can be easily concluded that decreasing the rolling resistance, or any other loss of power of the vehicle, a proportional reduction in force that the engine has to provide for the vehicle to move would be obtained, thus resulting in a reduction of fuel consumption.

Thus, a careful design of the pavements will maximize the fuel economy, reducing the energy consumption and gaseous emissions released to the atmosphere. Some 
authors argue that the option for rigid pavements can lead to fuel savings, given that the flexible pavements deform under the action of vehicles. Thus, a higher energy expenditure will be necessary for the movement (Taylor and Patten, 2006). Other authors claim that pavements with improved surface characteristics require a lower energy consumption compared with rougher or more irregular pavements (Amos, 2006; Bendtsen, 2004).

Despite this trend, Wang et al. (2012) have concluded that rehabilitation operations carried out in highway sections with high traffic volumes resulted in energy and greenhouse gas savings accrued during the use phase, due to reduced rolling resistance, that can be significantly larger than the energy use and greenhouse gas emissions from material production and construction. However, for low traffic volume highways, the rehabilitation may result in a net increase in energy use and greenhouse gas emissions if low traffic volumes and poor construction quality occur together. This conclusion reinforces the need to include this parameter in the life cycle assessments of the road pavements, so that every situation can be properly analyzed and weighted.

\section{Methodology and case study}

\subsection{Developed LCA methodology}

As mentioned above, most of the existing methodologies for Life Cycle Analysis of road pavements are essentially focused on the activities of extraction, production, transportation and application of materials, i.e., the construction of road, due to the difficulty of obtaining other relevant data. Taking into account that the use phase of the road is predominant with respect to energy consumption (fuel) and therefore to gas emissions released to the atmosphere (Huang et al., 2009b; Pérez-Martínez and Miranda, 2014), this approach intends to consider all stages of the life cycle, with 
special attention to the road use phase. One of the main factors to consider during this phase is the rolling resistance, which depends on the structural and surface characteristics of the different pavements. The methodology used in the present work allows the analysis and comparison of different pavements with respect to energy consumption and emissions related to their construction and use phases. Thus, this is a tool that could prove to be useful in the design phase of a road and influence the choice of the type and characteristics of the pavement.

\subsubsection{Conceptual organization of the methodology}

The developed methodology considers 5 phases of the life cycle of road pavements (materials extraction and production; construction; use; maintenance; and end of life), each with the following constitution:

1. Materials extraction and production: all inputs and outputs of the system are considered in this phase, including extraction and crushing of aggregates, production of binders (cement, bitumen or bitumen emulsion) and production of mixtures (bituminous or hydraulic). Also the transport of materials and mixtures was considered both at the jobsite and at the production plants, as well as the equipment and activities inherent to loading the trucks.

2. Construction: in this phase all activities necessary for pavement construction are considered such as earthworks, foundation reinforcement (when necessary) and application of pavement layers, considering the specific activities of each pavement type (rigid, semi-rigid or flexible).

3. Use: this methodology focuses a significant level of attention in this phase, considering aspects usually neglected by most of the existing methodologies. For this purpose, the differences in terms of rolling resistance and consequently of energy consumption and emissions released, which depend on the type of pavement and its characteristics, should be studied and its impact on the life 
cycle of the road assessed. This methodology allows the introduction of different consumption values, which may be obtained experimentally.

4. Maintenance: this phase comprises the operations that will be made on the road to ensure that adequate pavement conditions are maintained throughout its life. Depending on the strategy adopted by the road administration, preventive maintenance operations or more complex rehabilitation techniques can be implemented, including the replacement of the surface course or a pavement overlay.

5. End of life: the last phase occurs when the road reach the end of its useful life (for which it was designed).Again, depending on the strategy adopted by the road administration it will be possible to proceed to its recovery (reconstruction), demolition and removal of materials that may still be recycled or simply leave the road on site, solution that would also lead to a certain environmental burden.

The interactions between the various phases presented above and the energy/materials flows are schematically represented in Figure 1.

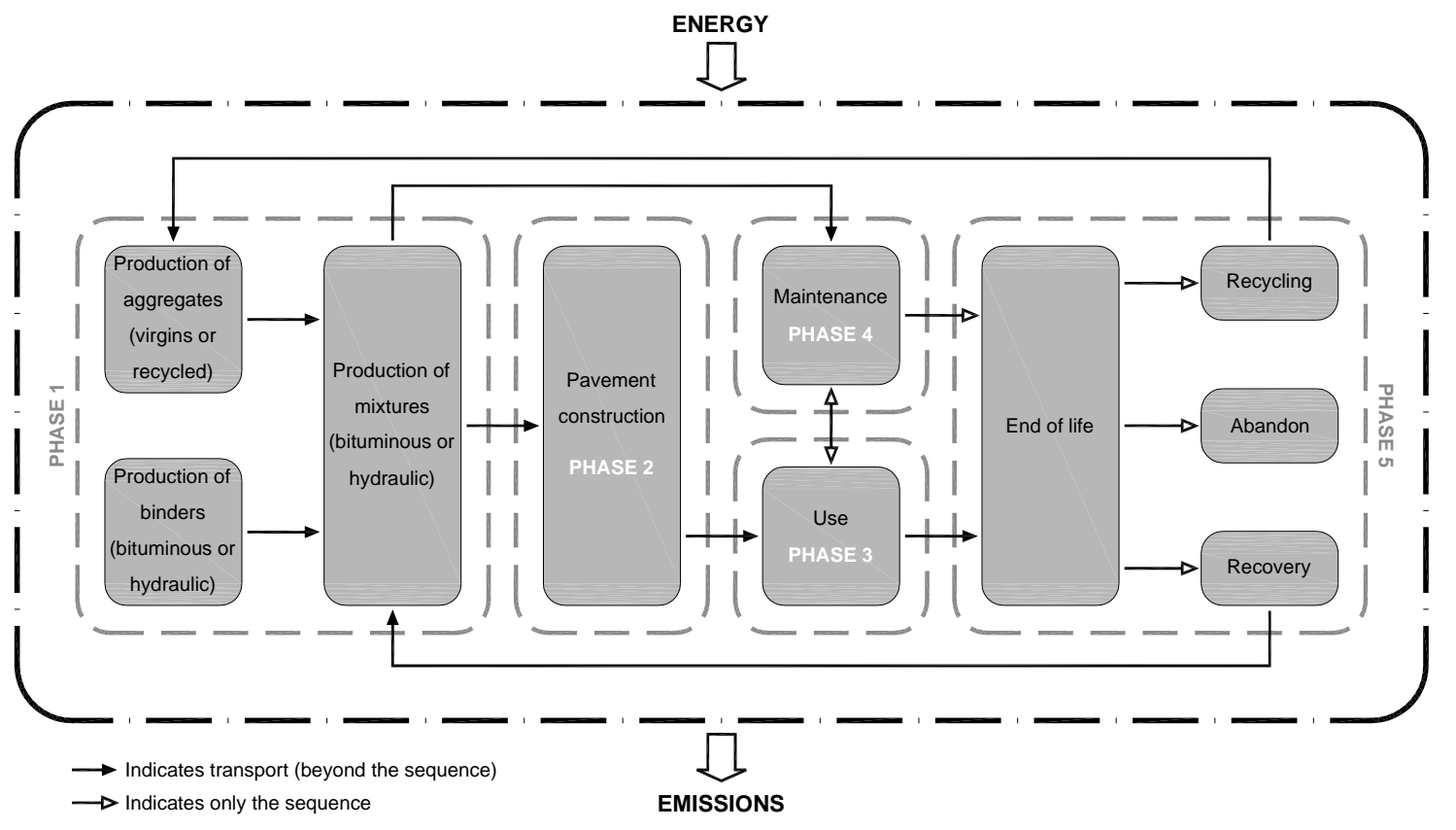

Figure 1. Energy/material flows and interactions between the phases of the road pavements life cycle 


\subsubsection{Functional unit}

All life cycle assessments use a reference unit known as the functional unit in order to allow the results obtained in different analyses (this is, for different pavement solutions) to be compared. The functional unit for road pavements is defined herein by their geometry, service life, and levels of traffic supported (Vidal et al., 2013). Thus, in order to compare the different pavements, the length and width of the road should be the same for all alternatives. The pavement thickness can vary and is determined (by conventional pavement design methods) so that all analyzed solutions are capable of withstanding the same design traffic within a similar service life.

It should be noted that in the case of road pavements, the definition of the functional unit will depend on the characteristics of each road, its lifetime and design traffic. Thus, comparisons between solutions for different roads, with different functional units, will be difficult to establish.

\subsubsection{Structure of the LCA methodology}

The developed methodology is divided into six worksheets, in which the various phases and components of the pavement life cycle are considered. The worksheets mentioned are organized as follows:

1. Characterization of the road: in the first worksheet, a characterization of the road and pavement is made, including the geometric characteristics, the pavement type to be used, the type and thickness of each pavement layer, as well as the indication of the average transport distances within the production plant, the jobsite and between both, with a view to subsequent determination of transport operations impacts. 
2. Material Characterization: in the second worksheet the materials and mixtures are characterized, namely their composition, through the definition of the percentages (by mass) of each constituent, and their densities (loose and compacted). These values serve as the basis for calculating the number of trips to be made by trucks for transportation.

3. Characterization of equipments/processes: in the third worksheet, the characterization of the various activities/processes, as well as the equipment to be used, is carried out. In this worksheet, the unitary consumption and emissions for each activity that makes up the life cycle can be determined.

4. Life Cycle Inventory ( $L C l)$ : the fourth worksheet corresponds to the inventory, itself, being its contents the target of the analysis carried out at this stage. This worksheet is the main output of the methodology, beginning by presenting a summary of the characteristics of the road and a detailed map of the quantities of materials and mixtures needed, followed by the presentation of consumptions and emissions that result from each activity, which are after presented in overall terms and grouped by impact categories, for analysis and comparison purposes.

One of the main impact categories to be taken into account in these analyses is the Global Warming Potential (GWP). The GWP is determined by converting $\mathrm{CO}_{2}, \mathrm{CH}_{4}$ and $\mathrm{N}_{2} \mathrm{O}$, due to their potential for the greenhouse effect, in $\mathrm{CO}_{2}$ equivalent emissions using the conversion factors of 1, 23 and 296, respectively (Huang et al., 2009b). Thus, the GWP can be determined by Equation 1.

$$
\mathrm{GWP}=\mathrm{CO}_{2}+23 \mathrm{CH}_{4}+296 \mathrm{~N}_{2} \mathrm{O}
$$

The determination of the equipment's energy consumption and the resulting gas emissions was obtained according to Equations (2) and (3), respectively. 


$$
T E C=\sum_{i=1}^{n} \sum_{j=1}^{m}\left(U F C_{i} \times U E C F_{i} \times V_{j}\right)
$$

Where TEC is the total energy consumption (J); UFC $i$ is the unitary fuel consumption of equipment $i\left(L / \mathrm{m}^{3}\right) ; U E C F_{i}$ is the unitary energy conversion factor of the fuel used in equipment $i(\mathrm{~J} / \mathrm{L}) ; V_{j}$ is the volume of material/mixture $j$ used $\left(m^{3}\right)$.

$$
\operatorname{TER}_{(g)}=\sum_{i=1}^{n} \sum_{j=1}^{m}\left(U E R_{(g)_{i}} \times U F C_{i} \times V_{j}\right)
$$

Where $T E R_{(g)}$ is the total emissions of the gas $g$ released $(\mathrm{kg}) ; U E R_{(g) i}$ the unitary emissions of the gas $g$ released by the equipment $i(\mathrm{~kg} / \mathrm{L}) ; U F C_{i}$ is the unitary fuel consumption of equipment $i\left(\mathrm{~L} / \mathrm{m}^{3}\right) ; V_{j}$ is the volume of material/mixture $j$ used $\left(\mathrm{m}^{3}\right)$.

5. Life Cycle Costs Analysis (LCCA): in the fifth worksheet an analysis of the costs of each alternative under study is carried out in order to provide the decision makers with an additional criterion for the selection of the most adequate solution (besides the other construction/maintenance related impacts).

6. Analysis of the road use phase: the sixth and last worksheet is the one that differentiates this methodology from most of the other existing methods, by analyzing the use phase of the road, quantifying the impacts that result from the traffic. Here, a prediction of the fuel consumed by the design traffic (during the lifetime of the road) is made, as well as their costs and gaseous emissions released to the atmosphere as a result of that fuel combustion. If experimental data that allow establishing comparisons of fuel consumption between pavements are available, this worksheet also determines the differences of the fuel, costs and emissions compared with a reference pavement (as presented below in the case study). The determination of the fuel consumption and the 
gaseous emissions released to the atmosphere by vehicles was based on the Equations (4) and (5), respectively.

$\operatorname{TFCV}_{\left(y_{0}-y_{n}\right)}=\sum_{i=1}^{m} A A D T V x_{i_{\left(y_{0}\right)}} \times 365 \times \frac{(1+t g)^{n}-1}{\operatorname{tg}} \times U F C V x_{i} \times d$

Where $\operatorname{TFCV}_{(y 0-y n)}$ is the total fuel consumption of the vehicles between the years 0 and $n(\mathrm{~L}) ; A A D T V x_{i(y 0)}$ is the average annual daily traffic of vehicles of type $x_{i}$ in the year 0 (with $x$ corresponding to light vehicles, heavy goods vehicles and heavy passenger vehicles); $t g$ is the traffic growth rate; $n$ is the number of years; UFCV $x_{i}$ is the unitary fuel consumption of vehicles of type $x_{i}$ $(\mathrm{L} / \mathrm{km}) ; d$ is the average vehicle travelled distance $(\mathrm{km})$.

$\operatorname{TERV}_{(g)_{\left(y_{0}-y_{n}\right)}}=\sum_{i=1}^{m} \operatorname{AADTV}_{i_{\left(y_{0}\right)}} \times 365 \times \frac{(1+t g)^{n}-1}{t g} \times U F C V x_{i} \times U E R V x_{i} \times d$

Where $T E R V_{(g)(y 0-y n)}$ is the total of emissions of the gas $g$ released by the vehicles between the years 0 and $n$ (ton); $A A D T V x_{i(y 0)}$ is the average annual daily traffic of vehicles of type $x_{i}$ in the year 0 (with $x$ corresponding to light vehicles, heavy goods vehicles and heavy passenger vehicles); $\operatorname{tg}$ is the traffic growth rate; $n$ is the number of the years; $U F C V x_{i}$ is the unitary fuel consumption of vehicles of type $x_{i}(\mathrm{~L} / \mathrm{km}) ; U E R V x_{i}$ is the unitary emissions of the gas $g$ released by the vehicles of type $x_{i}$ (ton/L); $d$ is the average vehicle travelled distance $(\mathrm{km})$.

Reference values obtained in the literature were used, by default, in each worksheet for the various calculations. However, the user has the possibility to change those values by others that may be considered most appropriate (for example, values obtained from experimental tests). 


\subsection{Case study}

The developed LCA methodology was applied to a specific case study. Four alternative pavement structures were analyzed, in order to evaluate the total environmental impact caused by each structural and surface solution, and in particular their energy consumption and global warming potential (GWP).

\subsubsection{Definition of the functional unit and the design traffic for the LCA study}

The functional unit for this LCA study was defined as a two lane road section with a length of $1.0 \mathrm{~km}$ and $9.0 \mathrm{~m}$ width (3.5 m per lane and $1.0 \mathrm{~m}$ per shoulder). The LCA period of analysis is 20 years, which is the usual expected life of an asphalt pavement. The design temperature selected for this case study was $20^{\circ} \mathrm{C}$.

The four alternative pavement structures were designed to support the same design traffic. The expected traffic per lane and per day (for each type of vehicle) in the year of the road opening to traffic is presented in Table 1. The expected traffic growth rate for this case study was $1 \%$ in the first 10 years and $3 \%$ in the remaining years, taking into consideration the current economical situation in the developed countries.

Table 1. Traffic per lane and per day in the year of the road opening to traffic

\begin{tabular}{ll}
\hline Type of vehicle & Number of vehicles per day \\
\hline Light passenger vehicles & 21174 \\
Heavy goods vehicles & 1347 \\
Heavy passenger vehicles & 44
\end{tabular}

The pavement design traffic is the accumulated heavy traffic during the pavement lifetime (20 years), which is converted into an equivalent number of standard axle loads 
of $80 \mathrm{kN}$ (ESALs) and was determined from the data presented in Table 1. This resulted in a design traffic of 92.1 million ESALs of $80 \mathrm{kN}$ for this case study, which is the last functional unit value used for the pavement design of the alternative structures under evaluation in this LCA study.

\subsubsection{Pavement design of the alternative structures}

In order to obtain alternative pavement structures with the same expected useful life period (20 years), the thickness of the several layers selected for each alternative pavement should be adjusted in order to support the same traffic design with the same damage at the end of the pavement life period. This is the pavement design phase.

As mentioned above, this LCA study aims to compare four alternative road pavement structures. These alternatives are being studied for the same road location. Therefore, it was assumed that the foundation (comprising the subgrade and a possible capping layer) and the granular layers should be kept constant (materials and thickness of layers) between the different pavement structures since the characteristics of this layers depend mostly on the properties of the existing soil. The capping layer of the foundation should be selected in order to assure a stiffness of $100 \mathrm{MPa}$ (Nunn, 2004). Both granular layers have a thickness of $15 \mathrm{~cm}$ and use crushed rock granular material, thus resulting in stiffness values of $200 \mathrm{MPa}$ and $400 \mathrm{MPa}$ for the sub-base and base granular layers, respectively. Thus, the differences between the four alternative pavement structures will only occur in the top three asphalt layers: surface, binder and base (Figure 2). In fact, different asphalt mixtures will be used for each pavement alternative, and this will change the thickness values of each layer obtained during the design of the four pavement alternatives in order to obtain an equivalent life period. 


\begin{tabular}{ccc}
\hline Asphalt Surface Layer (Mix1 or Mix 2) & $\begin{array}{c}+ \\
\text { Variable } \\
\text { dimensions } \\
\text { and } \\
\text { characteristics }\end{array}$ \\
Asphalt Binder Layer (Mix 3 or Mix 4) & $400 \mathrm{MPa}$ \\
Granular Base & $200 \mathrm{MPa}$ & \\
Foundation & $100 \mathrm{MPa}$ &
\end{tabular}

Figure 2. Schematic representation of the reference pavement structure used in the present study for all alternatives

Two different types of asphalt mixtures were defined to be used in the surface layer of the alternative pavement structures: Mix $1-$ a conventional asphalt surface mixture (AC14 surf 35/50) with a 35/50 bitumen or; Mix 2 - a slightly smoother asphalt surface mixture produced with a Polymer Modified Bitumen or PMB (AC14 surf PMB 25/55-65). Other two types of asphalt mixtures were selected for the binder and base layers of the alternative pavement structures: Mix 3 - a conventional asphalt binder and/or base mixture (AC20 bin 35/50 and AC20 base 35/50) with a 35/50 bitumen or; Mix $4-$ a recycled asphalt binder and/or base mixture produced with 50\% Reclaimed Asphalt Pavement or RAP (AC20 bin 35/50 + 50\% RAP and AC20 base 35/50 + 50\% RAP).

The four types of asphalt mixtures used in this LCA study are presented in Table 2, as well as their composition and stiffness modulus. The stiffness moduli of all studied mixtures were obtained in previous works (Araújo et al., 2013; Pereira et al., 2004; Silva et al., 2011), by using the four-point bending test method presented in EN 1269726 (2004) standard. 
Table 2. Types of asphalt mixtures used, their composition and characteristics

\begin{tabular}{|c|c|c|c|c|c|}
\hline Mixture & & & & RAP & Stiffness \\
\hline Label & Type & $(\% \mathrm{w} / \mathrm{w})$ & $(\% \mathrm{w} / \mathrm{w})$ & $(\% \mathrm{w} / \mathrm{w})$ & $\begin{array}{l}\text { at } 20^{\circ} \mathrm{C} \\
(\mathrm{MPa})\end{array}$ \\
\hline Mix_1 & AC14 surf $35 / 50$ & 95.0 & 5.0 & - & 4400 \\
\hline Mix_2 & AC14 surf PMB 25/55-65 & 95.0 & 5.0 & - & 5600 \\
\hline Mix_3 & $\begin{array}{l}\text { AC20 bin } 35 / 50 \\
\text { AC20 base } 35 / 50\end{array}$ & 95.0 & 5.0 & - & 5900 \\
\hline Mix_4 & $\begin{array}{l}\text { AC20 bin } 35 / 50+50 \% \text { RAP } \\
\text { AC20 base } 35 / 50+50 \% \text { RAP }\end{array}$ & 47.5 & 2.5 & 50.0 & 8100 \\
\hline
\end{tabular}

The four mixtures were also characterized in other works (Araújo et al., 2013; Pereira et al., 2004; Silva et al., 2011) concerning their fatigue resistance performance, according to EN 12697-24 (2004) standard, also using the four-point bending beam test method. This property is particularly important for base mixtures (mix_3 and mix_4), because the pavement design method is based on the relationship between the traffic design and the maximum allowable strain in this bottom asphalt layer of the pavement.

The mixtures can be grouped as mixtures for the surface layer (mix_1 and mix_2, respectively a conventional mixture a PMB mixture with a smoother surface) and as mixtures for binder/base layers (mix_3 and mix_4, respectively a conventional mixture and a recycled mixture). Taking this into account, the distribution of the mixtures used in each alternative pavement structure is presented in Table 3. 
Table 3. Four alternative pavement structures selected to evaluate the relative influence of the surface and the structural (binder and base) layers in the LCA study

Surface layer alternatives

\begin{tabular}{lccc}
\cline { 3 - 4 } & & Conventional (Mix_1) & Smooth PMB (Mix_2) \\
\hline & Conventional & Alternative Structure 1 & Alternative Structure 2 \\
& Surf layer: Mix_1 & Surf layer: Mix_2 \\
Binder and & (Mix_3) & Bin layer: Mix_3 & Bin layer: Mix_3 \\
Base layer & & Base layer: Mix_3 & Base layer: Mix_3 \\
\cline { 2 - 4 } alternatives & & Alternative Structure 3 & Alternative Structure 4 \\
& Recycled & Surf layer: Mix_1 & Surf layer: Mix_2 \\
& (Mix_4) & Bin layer: Mix_4 & Bin layer: Mix_4 \\
& & Base layer: Mix_4 & Base layer: Mix_4 \\
\hline
\end{tabular}

The four alternative pavement structures were designed using BISAR 3.0 software (Shell, 1998) in order to obtain an equivalent service life, based on the stiffness and fatigue life characteristics of the materials, through an iterative process until the design criteria are fulfilled. In the design of all pavement structure alternatives, the different layers were considered fully bonded (no slip between layers) and a Poisson's ratio of 0.35 was used for all layers, including the foundation. The results of the pavement design are presented in Table 4.

Table 4. Layer thickness $(m)$ values obtained for the alternative pavement structures

\begin{tabular}{lllll}
\hline Layer & Structure 1 & Structure 2 & Structure 3 & Structure 4 \\
\hline Surface layer & 0.04 & 0.04 & 0.04 & 0.04 \\
Binder layer & 0.07 & 0.06 & 0.08 & 0.07 \\
Base layer & 0.10 & 0.10 & 0.10 & 0.10 \\
Granular Base & 0.15 & 0.15 & 0.15 & 0.15 \\
Granular Sub-base & 0.15 & 0.15 & 0.15 & 0.15 \\
\hline
\end{tabular}


Despite of the differences in the stiffness modulus of the mixtures with and without RAP, the pavement design results of the four alternative structures are similar (with a maximum difference of $2 \mathrm{~cm}$ between structures 2 and 3, assumed as occurring in the binder layer). In fact, the experimental stiffness and fatigue life results have an opposite effect in the design of the structures with recycled base mixtures (this mixture has higher stiffness, which decreases the strain level in the structure and its thickness, but it also has a lower fatigue resistance, which demands an increased thickness).

\subsubsection{Laboratory evaluation of energy consumption variation associated with different} rolling resistances of the surface layers

The rolling resistance may influence the LCA of road pavements (mainly at the use phase), and this is the main reason to select two different surface layers in the present study: a conventional asphalt mixture and a polymer modified binder (PMB) asphalt mixture (smoother than the conventional mixture).

The laboratory assessment of the energy consumption variation associated with the different rolling resistances of both surface layer mixtures was carried out with an adapted Wheel Tracking Test (WTT) apparatus. This equipment simulates a wheel rolling over a road surface, and it can be used to establish some relationships between the energy consumption required to move the wheel and the variation of the circulation conditions, including the surface characteristics (Araújo et al., 2013).

Thus, the aim of this adapted WTT test is to evaluate the energy consumption required to move the wheel of the apparatus over different mixtures with some structural and surface characteristics. The energy consumption of the electrical motor of this apparatus is that required to move the wheel (which can apply different load values) over the asphalt mixture specimen. The energy consumption variation between two 
different surfaces is an indirect quantification of their relative rolling resistances. This process used to evaluate the energy consumption associated to rolling resistance within the WTT apparatus simulates, to some extent, the effect of the rolling resistance in a real road pavement, which changes the fuel or energy consumption of the vehicles circulating over different road surfaces.

The power source of the equipment was connected to a multimeter in order to record the power consumption of the electrical motor, which in turn is monitored on a PC using a data acquisition system (this process was used for energy consumption evaluation).

Araújo et al. (2013) have previously presented the laboratorial evaluation of energy consumption variation associated with different rolling resistances of the two mixtures used in this LCA study for the surface layer, which were obtained with this adapted WTT procedure. In that work, it was concluded that the energy consumption of the smoother surface layer with polymer modified binder (mix_2: AC14 surf PMB 25/55-65) was $2.23 \%$ lower than that of the conventional surface layer (mix_1: AC14 surf 35/50). This reduction of the energy consumption due to the rolling resistance is in line with those values presented by previous works (Hultqvist, 2013; Milachowski et al., 2011).

As mentioned previously, the LCA method present in this paper aims to give a special attention to the use phase, namely by assessing the variation in the impacts of the project traffic when surface layers with different rolling resistances are used.

Thus, the LCA method used in this study estimated of the total amount of fuel and/or energy consumption over the lifetime of the pavement, and the gaseous emissions caused by the combustion of that fuel, considering the project traffic defined in the functional unit and the average values of fuel consumption for different types of vehicles. Furthermore, the laboratory data obtained for the energy consumption 
variation associated with different rolling resistances of the surface layers used in the alternative pavement structures was used to determine the corresponding reduction that occurs in the above parameters, during the use phase of the LCA method, when mix_2 is used instead of mix_1.

\section{Results and Discussion}

Taking into account the functional unit under evaluation, the results of the LCA method developed for this study are presented and discussed in this section. Initially, the detailed map of materials needed (resources consumption) to build each alternative pavement structure are presented, followed by the LCA results (global and per construction activity) during the construction phase, namely the energy consumption and gas emissions. Next, the LCA results for the use phase of the road, which were computed for the design traffic taking into consideration the different rolling resistances of the surface courses, are shown. Finally, the relative impact of the construction and use phases in the LCA results are discussed, especially to understand their influence in the decision-making of the LCA method (e.g. selection of more sustainable construction methods - recycling - or more sustainable surfaces during the use of the road - lower rolling resistance).

\subsection{Resources consumption}

All four alternative pavement structures are composed by two granular layers (base and sub-base), each with a thickness of $0.15 \mathrm{~m}$. Thus, 5265 tons of granular material will be needed to build these layers for the selected LCA functional unit of the road.

However, the properties and the thickness of the asphalt layers are different between the four alternative pavement structures analyzed. Thus, Table 5 summarizes the materials used (resources consumption, divided by new aggregates, new bitumen and 
reclaimed asphalt pavement - RAP) during the construction of the asphalt layers of each alternative pavement structure for the selected LCA functional unit of the road.

Table 5. Resources consumption in the asphalt layers for the LCA functional unit

\begin{tabular}{llll}
\hline Structure & New aggregates (ton) & New bitumen (ton) & RAP (ton) \\
\hline Structure 1 & 4219 & 222 & - \\
Structure 2 & 4019 & 212 & - \\
Structure 3 & 2612 & 137 & 1904 \\
Structure 4 & 2512 & 132 & 1798 \\
\hline
\end{tabular}

These results clearly show the advantage of using recycling technologies in the construction of road pavements (structures 3 and 4), since they can significantly reduce the use of new materials. The use of $\mathrm{PMB}$ asphalt mixtures in the surface layer (structures 2 and 4), with a higher stiffness modulus, have also slightly reduced the resources consumption due to the thickness reduction result of the pavement design.

\section{2. $L C A$ results from the construction phase}

\subsubsection{Global energy consumption and gas emissions during pavement construction}

The most obvious impacts typically imputed to road pavements are those related to the consumption of raw materials and the construction/maintenance operations. The inherent operations of each one of these activities lead to a certain energy consumption and the consequent release of gaseous emissions to the atmosphere.

The final results of the energy consumption and the gaseous emissions released to the atmosphere, and the corresponding global warming potential, concerning the 
construction phase of the alternative pavements structures under study, are shown in Table 6 for the LCA functional unit of the road.

Table 6. Energy consumption, gaseous emissions and GWP of the LCA functional unit during pavement construction

\begin{tabular}{lllll}
\hline LCA result & Structure 1 & Structure 2 & Structure 3 & Structure 4 \\
\hline Energy consumption (TJ) & 2.04 & 1.95 & 1.98 & 1.89 \\
\hline $\mathrm{CO}_{2}$ (ton) & 121.64 & 116.44 & 104.35 & 100.41 \\
$\mathrm{CH}_{4}(\mathrm{~kg})$ & 0.06 & 0.06 & 0.05 & 0.05 \\
$\mathrm{~N}_{2} \mathrm{O}(\mathrm{kg})$ & 0.75 & 0.72 & 0.63 & 0.61 \\
\hline $\mathrm{GWP}\left(\mathrm{CO}_{2}\right.$-eq tons) & 121.86 & 116.66 & 104.54 & 100.59 \\
\hline $\mathrm{SO}_{2}$ (ton) & 0.22 & 0.21 & 0.167 & 0.161 \\
$\mathrm{NO}_{\times}$(ton) & 0.62 & 0.59 & 0.520 & 0.502 \\
\hline
\end{tabular}

Structures 2, 3 and 4 apply more sustainable construction processes in comparison with the conventional structure 1 . The ratio between the LCA results of the alternative structures and the conventional structure 1 is presented in Figure 3 , thus clarifying the ability of all alternatives to reduce the energy consumption and gaseous emissions.

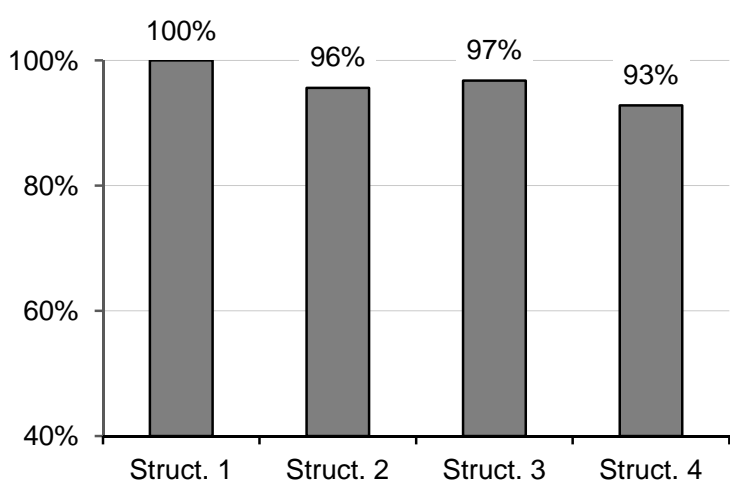

a) Energy consumption

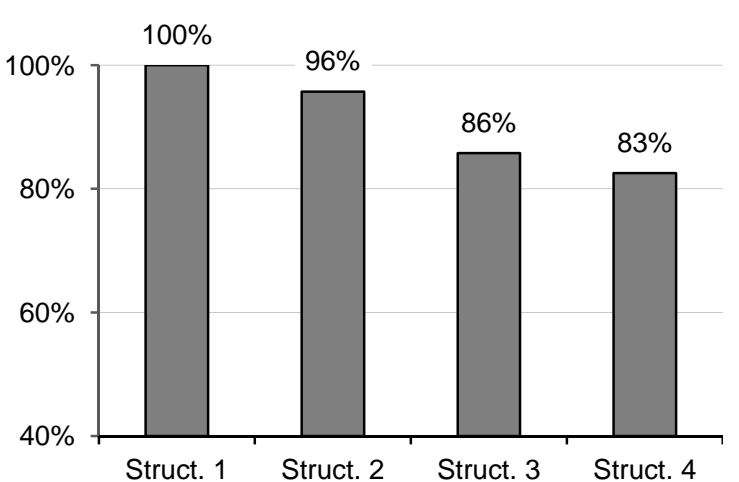

b) GWP

Figure 3. Energy consumption and GWP of the LCA functional unit during pavement construction: ratio between the alternative structures and the conventional structure (1) 
Concerning the reduction of the energy consumption, the use of a stiffer PMB mixture in the surface layer ( $4 \%$ in structure 2 ) has slight advantages in comparison with the use of a recycled mixture in the bottom layers (3\% in structure 3$)$. This result is a consequence of the higher thickness of structure 3 (due to its lower fatigue resistance), and the higher temperatures used in the production of recycled mixtures. Structure 4 joins both advantages of structures 2 and 3 , thus being the best solution with a reduction of $7 \%$ in the energy consumption.

The main advantage of using recycled technologies is observed when measuring the gaseous emissions or the GWP of the different alternatives, especially due to the reduction of emissions associated with the extraction of raw materials. In fact, the use of recycled mixtures (structure 3) enables a reduction of gaseous emissions to $14 \%$ for $\mathrm{CO}_{2}, 23 \%$ for $\mathrm{SO}_{2}$ and approximately $15 \%$ for the remaining gases. The reduction of the GWP of structure 2 (surface layer with PMB mixture) is clearly lower (4\%), while structure 4 presents the maximum reduction of $17 \%$ in the GWP.

\subsubsection{Energy consumption and gas emissions during each pavement construction activity}

The LCA results of the pavement construction phase were also divided in four groups of activities in order to evaluate their relative influence on the results obtained, namely for transport operations, extraction of raw materials, in-plant production of mixtures and in-situ operations. The energy consumption and gaseous emissions (shown, in this case, through the global warming potential - GWP) of each construction activity, for all alternative pavement structures, are presented in Table 7 . Then, the relative weight of each activity in the total energy consumption and GWP of each alternative structure is presented in Figure 4. 
Table 7. Energy consumption (TJ) and GWP (tons of $\mathrm{CO}_{2}-\mathrm{eq}$ ) of the LCA functional unit caused by each construction activity

\begin{tabular}{llllll}
\hline LCA result & Stage & Structure 1 & Structure 2 & Structure 3 & Structure 4 \\
\hline Energy & Transport & 0.25 & 0.25 & 0.22 & 0.22 \\
consumption & Raw materials & 0.28 & 0.27 & 0.18 & 0.17 \\
$(\mathrm{TJ})$ & Mixtures production & 1.46 & 1.39 & 1.53 & 1.46 \\
& In-situ operations & 0.05 & 0.05 & 0.05 & 0.05 \\
& & & & & 17.72 \\
\hline GWP & Transport & 20.09 & 19.50 & 17.30 \\
(tons of & Raw materials & 46.18 & 44.01 & 28.79 & 27.70 \\
$\mathrm{CO}_{2}$-eq) & Mixtures production & 51.27 & 48.83 & 53.71 & 51.27 \\
& In-situ operations & 4.32 & 4.32 & 4.32 & 4.32 \\
& & & & & \\
\hline
\end{tabular}

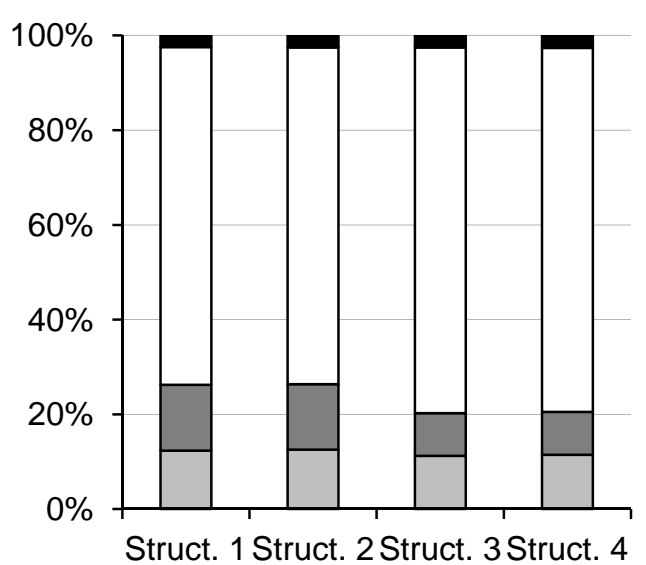

a) Energy consumption

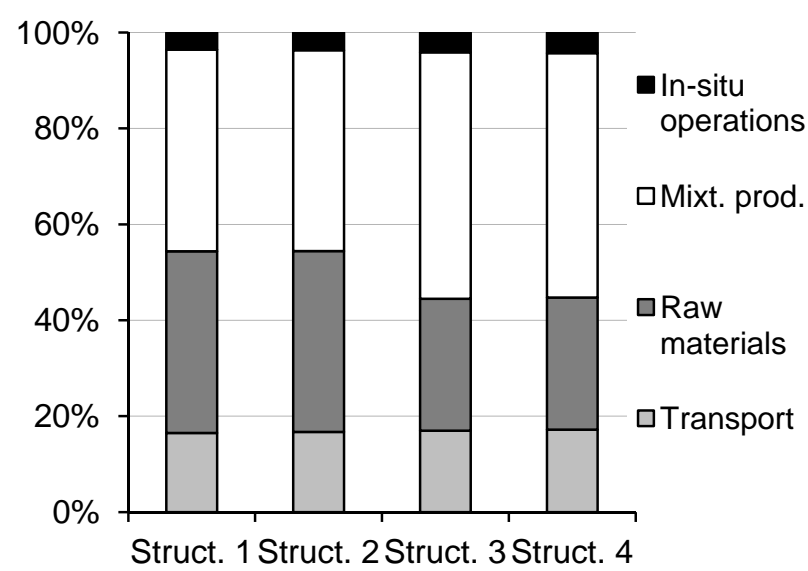

b) GWP

Figure 4. Comparison of the energy consumption and GWP caused by each construction activity

The production of asphalt mixtures is the construction activity with higher energy consumption for all alternative pavement structures, using always more than $70 \%$ of the energy needed for all the construction activities. This value increases to more than $75 \%$ in structures 3 and 4 due to the use of a recycled mixture, which is produced at higher temperatures and has lower energy consumption during the extraction of raw 
materials. On the other hand, the use a PMB mixture in the surface layer (structure 2) barely changes the energy consumption and GWP relative weight of the different construction activities.

The impact of the production activity is less significant concerning the gaseous emissions (GWP) than the energy consumption, although it is still the activity with higher contribution for the gaseous emissions. In fact, for all alternative structures, the two phases with higher influence on the GWP value are the extraction of raw materials and the mixture production. Moreover, the main difference between the relative weights of each construction activity in the GWP results from the use of recycled mixtures. Thus, the GWP contribution of the structures without recycled mixtures (structures 1 and 2 ) is $16.6 \%$ for transport operations, $37.8 \%$ for extraction of raw materials, $42.0 \%$ for mixture production and 3.6\% for in-situ operations. The GWP contribution of the structures with recycled mixtures (structures 3 and 4) for the same activities is, respectively, $17.1 \%, 27.5 \%, 51.2 \%$ and $4.2 \%$.

In order to identify the activities which are mainly responsible for the reduction of energy consumption and GWP of the structures 2,3 and 4 , it is fundamental to calculate the ratio between the LCA results of each alternative structure and the conventional structure (1) for all construction activities. The ratios obtained for energy consumption and for GWP are similar, and thus both are simultaneously presented in Figure 5.

The reduction of the energy consumption and GWP in Structure 2 (PMB mixture in the surface layer) is caused by the reduction of the asphalt thickness of this alternative pavement, which influences the transport, extraction of raw materials and mixture production activities. On the other hand, in Structure 3 (recycled mixtures in binder/base layers) there is a massive reduction in the energy consumption and GWP 
during the extraction of raw materials, which also impacts the transport activity. However, there is an increase in the energy consumption and GWP during the production of mixtures due to the higher thickness of this structure and the higher temperatures used during production. Structure 4 used both alternative mixtures (PMB and recycled), and thus it is the most sustainable solution considering the energy consumption and GWP.

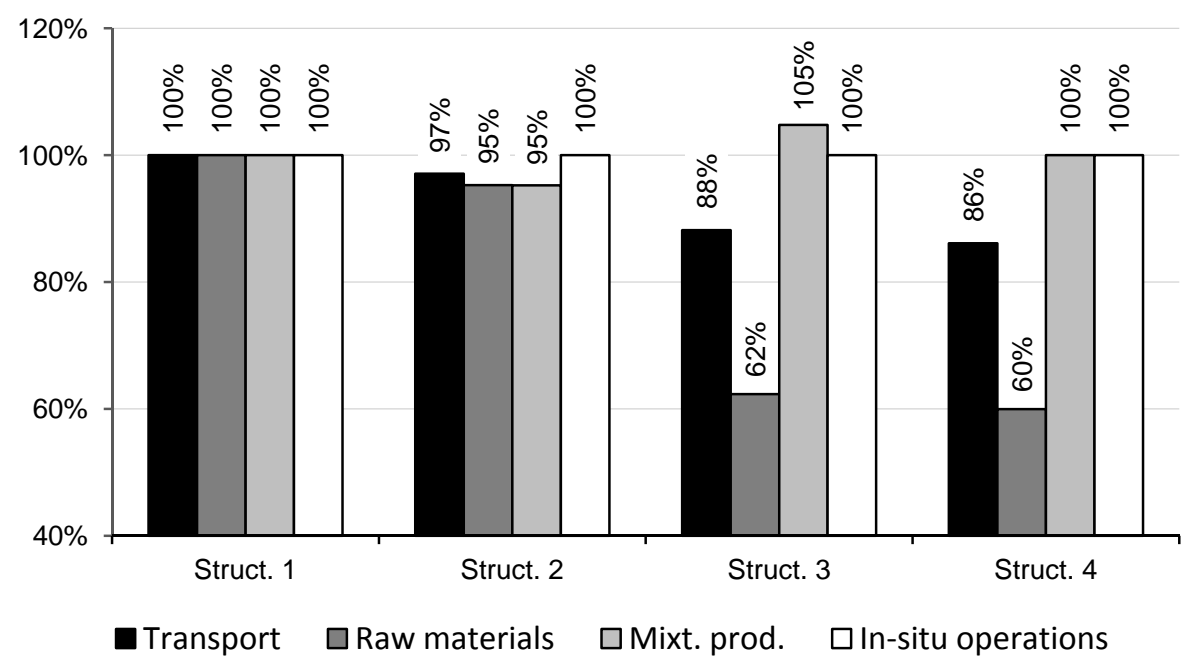

Figure 5. Energy consumption and GWP of the LCA functional unit during the pavement construction: ratio between the alternative structures and the conventional structure (1)

\subsection{LCA results from the use phase}

A reduction in the energy consumption of $2.23 \%$ was observed in the laboratory when a mixture with lower rolling resistance (PMB asphalt mixture, used in structures 2 and 4) was used as a surface course material instead of a conventional asphalt mixture (structures 1 and 3). Taking into account that difference and the design traffic presented in the functional unit of the LCA method, it was possible to calculate the 
energy consumption and gaseous emissions associated with the use phase for this case study (Table 8).

Table 8. Energy consumption, gaseous emissions and GWP of the LCA functional unit during pavement use phase

\begin{tabular}{lllll}
\hline LCA result & Structure 1 & Structure 2 & Structure 3 & Structure 4 \\
\hline Energy consumption (TJ) & 1470 & 1437 & 1470 & 1437 \\
\hline $\mathrm{CO}_{2}\left(\times 10^{3}\right.$ ton) & 118.37 & 115.73 & 118.37 & 115.73 \\
$\mathrm{CH}_{4}$ (ton) & 44.26 & 43.27 & 44.26 & 43.27 \\
$\mathrm{~N}_{2} \mathrm{O}$ (ton) & 17.70 & 17.31 & 17.70 & 17.31 \\
\hline $\mathrm{GWP}\left(\mathrm{x} 10^{3} \mathrm{CO}_{2}\right.$-eq tons) & 124.63 & 121.85 & 124.63 & 121.85 \\
\hline $\mathrm{SO}_{2}$ (ton) & 55.64 & 54.40 & 55.64 & 54.40 \\
$\mathrm{NO}_{x}$ (ton) & 640.10 & 625.82 & 640.10 & 625.82 \\
\hline
\end{tabular}

By changing a conventional surface layer (AC14 surf 35/50 - structures 1 and 3 ) to a new surface layer with lower rolling resistance (AC14 surf PMB 25/55-65 - structures 2 and 4), it was possible to quantify a reduction in the energy consumption of $33 \mathrm{TJ}$, as well as a reduction of the gaseous emissions of 2780 tons of $\mathrm{CO}_{2}$-eq for the GWP, 1.2 tons of $\mathrm{SO}_{2}$ and 14.3 tons of NOx during the road LCA use phase. These values were obtained and are only valid for the selected LCA functional unit, for a lifetime of 20 years and a high volume of traffic, since the use phase results are very dependent on these two parameters.

Moreover, it is fundamental to understand the relative influence of these use phase results in comparison with the LCA results obtained in the construction phase, in order to understand its relative weight in the decision-making process. 


\subsection{Comparison between the LCA results of construction and use phases}

Comparing the energy consumption and the gaseous emissions during the use phase and those obtained from the construction operations (Figure 6), it is clear that the road use phase has a dominant influence on the global LCA results.

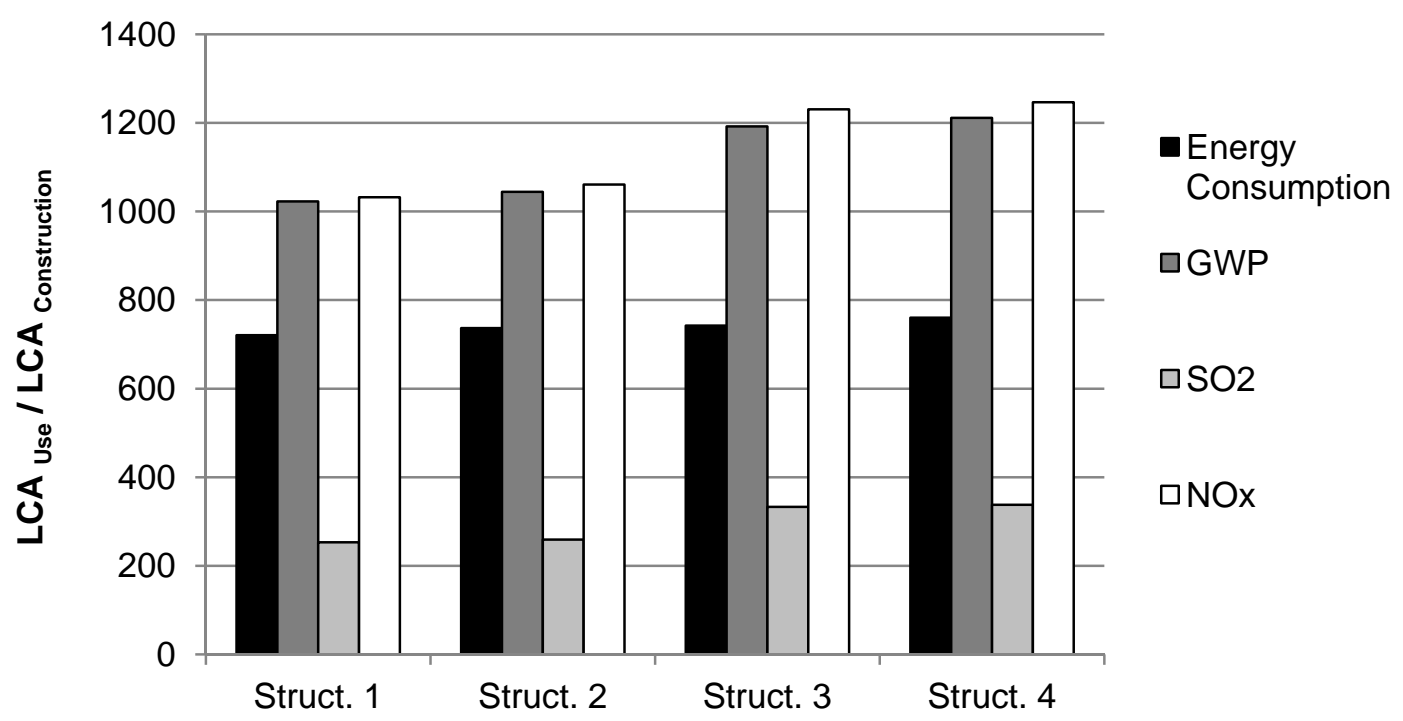

Figure 6. Ratio between the LCA results of the use phase and the construction phase

By comparing the mentioned values, it is noted that energy consumption observed during the use phase is about 700 times higher than that of the construction phase. The GHG emissions $\left(\mathrm{CO}_{2}, \mathrm{CH}_{4}\right.$ and $\left.\mathrm{N}_{2} \mathrm{O}\right)$ and $\mathrm{NO}_{x}$ during the road use phase are more than 1000 times higher than those from the pavement construction. The emissions of $\mathrm{SO}_{2}$ during the use phase are, on average, 300 times higher than those released during construction. It is also possible to conclude that the gaseous emissions ratios are higher for structures 3 and 4 , due to the lower values of emissions in the construction phase, which are related to the lower use of raw materials of the recycled mixtures. 
Taking into account that alternative structure 4 was the most sustainable solution obtained in the LCA study both in the construction and use phase, it is important to quantify the differences between that alternative and the conventional one, which are presented in Figure 7.

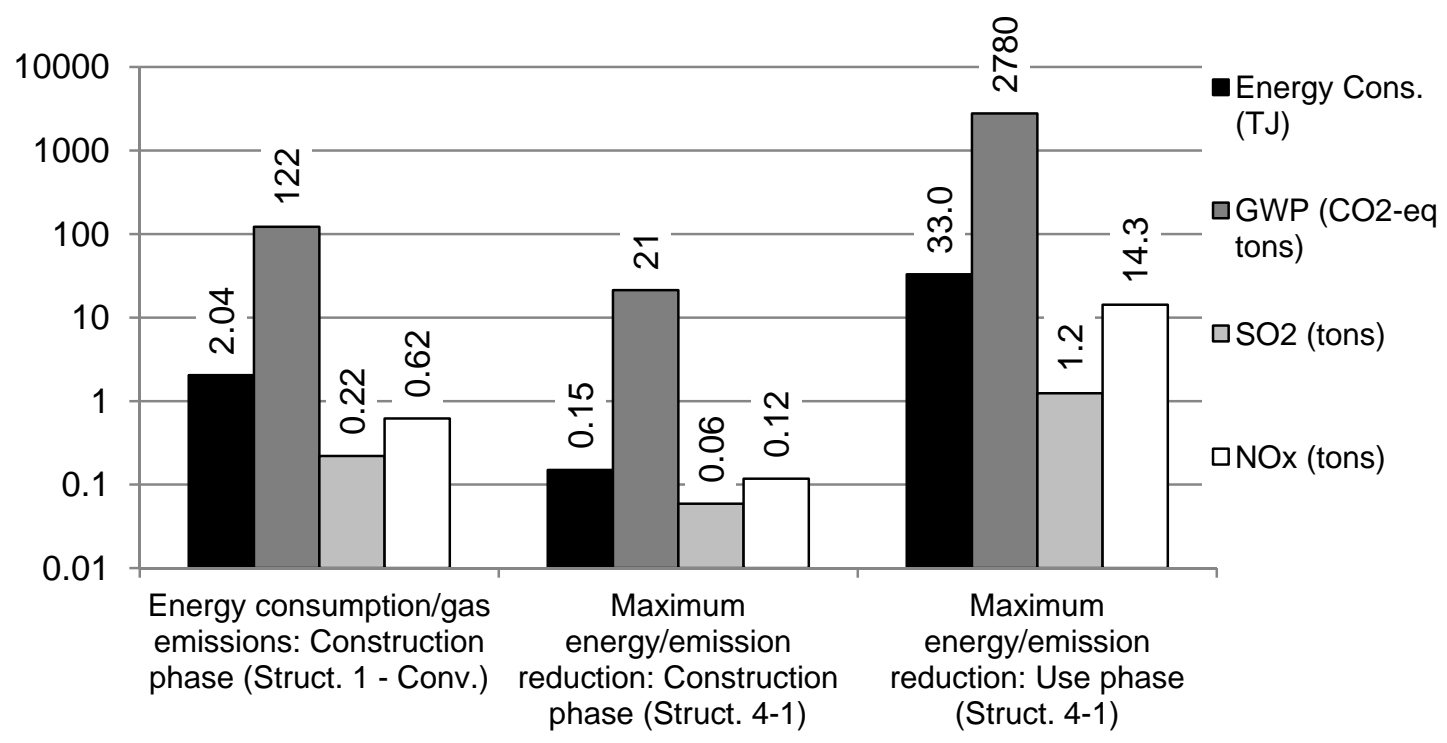

Figure 7. Maximum reductions of the construction and use phases in comparison with the energy consumption or gas emissions obtained in the construction of the conventional structure (1)

It is clear that during the use phase the reduction of energy consumption (33 $\mathrm{TJ})$ and gaseous emissions (2780 tons of CO2-eq, 1.2 tons of SO2 and 14.3 tons of NOx) is higher than the equivalent reduction during the construction phase $(0.15 \mathrm{TJ} ; 21$ tons of CO2-eq, 0.06 tons of SO2 and 0.12 tons of NOx). Thus, the selection of alternative structure 4 will bring more evident benefits during the use phase. Furthermore, the reductions observed during the use phase are even significantly higher than all the energy consumed and gases emitted for the construction of the conventional solution.

The ratios of the reductions previously mentioned for the use phase with the total energy consumption/gaseous emissions of the conventional pavement alternative 
construction, as well as with the corresponding reductions during the construction phase are presented in Figure 8.

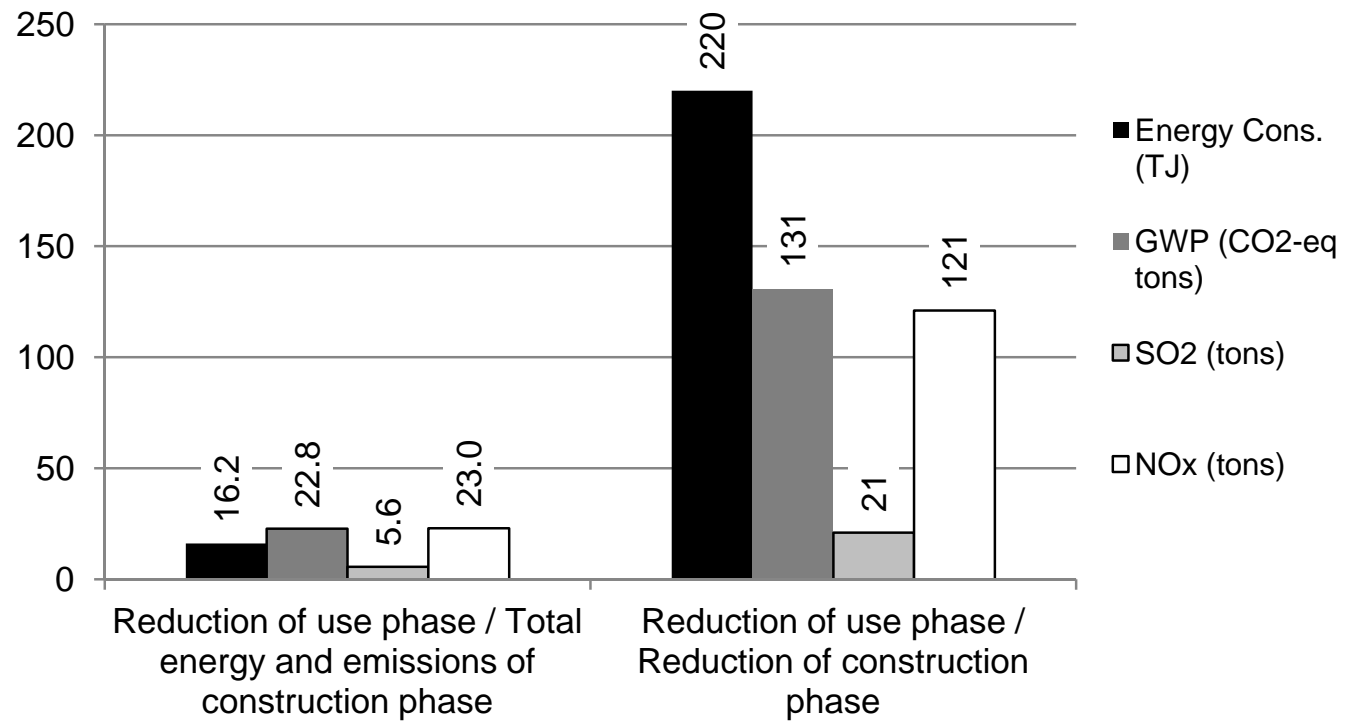

Figure 8. Ratios between the reductions of the use phase and the LCA results/reductions of the construction phase

The combination of the most sustainable solutions in alternative structure 4 results in a reduction of the energy consumption and GHG emissions during the pavement lifetime (in comparison with the conventional pavement structure) that is, respectively, 16.2 and 22.8 times higher than the corresponding values necessary for the pavement construction, taking into account the functional unit described in the paper. The same tendency is observed for the other gases, with values 5.6 and 23 times higher respectively for $\mathrm{SO}_{2}$ and $\mathrm{NOx}$. All these values show that the impacts of the road construction phase could quickly be offset by simply using a smoother surface course with lower rolling resistance, due to the great reduction in the impact during the use phase.

When the maximum reductions (between alternative structures 4 and 1 ) obtained during the use phase are compared with the corresponding reductions of the 
construction phase, the ratios are overwhelming, showing that it is imperative to consider the use phase in the LCA of road pavements in order to have an additional and very important tool for decision-making processes.

Even though other variables could be included in the LCA, namely, the depletion of natural resources and the economical and social effects of using recycled materials, this paper demonstrates the importance of the use phase of the road and proves that this cannot be neglected in Life Cycle Assessments.

\section{Conclusions}

Based on a new methodology developed for Life Cycle Assessment of road pavements, the present paper carried out an LCA of different pavement structures, with the objective of analyzing the use of more sustainable construction alternatives at both the construction and the use phase of the road, in terms of energy consumption and gaseous emissions. The main conclusions that can be drawn from the results obtained are as follows:

- The energy consumption and corresponding GHG emissions of the design traffic during the pavement lifetime is significantly higher than that of the construction phase; moreover, the reductions that can be obtained by applying a surface course with a lower rolling resistance may be substantially higher than those of the construction phase.

- The use of recycled materials in the asphalt layers may reduce even further the gaseous emissions of the construction phase, mainly due to the reduction in the emissions observed during the extraction of raw materials (in this case study the incorporation of 50\% RAP allowed a reduction in the energy consumption of $3 \%$ and a reduction of gaseous emissions of $14 \%$ for $\mathrm{CO}_{2}, 23 \%$ for $\mathrm{SO}_{2}$ and approximately $15 \%$ for $\mathrm{CH}_{4}, \mathrm{~N}_{2} \mathrm{O}$ e $\mathrm{NO}_{\mathrm{x}}$ ). 
- The importance of the use phase was also demonstrated by comparing the emissions released in the road use phase with those of the construction phase. The energy consumption observed during the use phase is about 700 times higher than that obtained during construction, while GHG and NOx emissions released by the vehicles during the road lifetime are more than 1000 times higher than the corresponding gases released in the construction phase.

- The combination of the most sustainable solutions in structure 4, including the use of recycled materials in the lower asphalt layers and the use of a smoother surface course, results in a reduction of the energy consumption and GHG emissions during the pavement lifetime that is, respectively, 16 and 23 times higher than the corresponding values necessary for the pavement construction, taking into account the functional unit described in the paper.

- Even though other variables could be included in the LCA, namely, the depletion of natural resources and the economical and social effects of using recycled materials, this paper demonstrates the importance of the use phase of the road and proves that this cannot be neglected in Life Cycle Assessments.

- To improve the approach used in this work, an improved process of measuring energy consumption from different pavement surfaces/structures (using a real scale tire/pavement interaction system) is planned be used in the future to validate the percentage of energy reduction presented in this paper.

\section{Acknowledgements}

The authors would like to acknowledge the support given by the Portuguese Foundation for Science and Technology (FCT) to the Territory, Environment and Construction Centre, through the project PTDC/ECM/119179/2010 and the strategic project PEst-OE/ECI/UI4047/2014. 


\section{References}

Adrian, W., Jobanputra, R., 2005. Influence of pavement reflectance on lighting for parking lots. Skokie, IL: Portland Cement Association. PCA R\&D Serial No. 2458.

Amos, D., 2006. Pavement Smoothness and Fuel Efficiency: An Analysis of the Economic Dimensions of the Missouri Smooth Road Initiative. Missouri Department of Transportation, Organizational Results Research Report, Report No. OR 07-005.

Araújo, J.P.C., Oliveira, J.R.M., Silva, H.M.R.D., Sampaio, J., Palha, C., 2013. Evaluation of the influence of the surface layer on the sustainability of road pavements., $7^{\circ}$ Congresso Rodoviário Português, Lisbon, Portugal (in Portuguese).

ASCE, 2008. ETHICS - Guidelines for Professional Conduct for Civil Engineers. American Society of Civil Engineers.

Bendtsen, H., 2004. Rolling resistance, fuel consumption - a literature review. Road Directorate, danish Road Institute, Denmark.

Bragança, L., Mateus, R., 2012. Life-cycle analysis of buildings: Environmental impact of building elements. iiSBE Portugal, Portugal.

Brandt, H.C.A., De Groot, P.C., 2001. Aqueous leaching of polycyclic aromatic hydrocarbons from bitumen and asphalt. Water Research 35(17), 4200-4207.

CIB, 1999. Agenda 21 on sustainable construction. CIB Report Publication 237. ISBN: 90-6363-015-8.

EAPA/Eurobitume, 2004. Environmental Impacts and Fuel Efficiency of Road Pavements. EAPA/Eurobitume, Industry Report, March 2004.

EN 12697-24, 2004. Bituminous mixtures - Test methods for hot mix asphalt - Part 24: Resistance to fatigue. European Committee for Standardization, Brussels.

EN 12697-26, 2004. Bituminous mixtures - Test methods for hot mix asphalt - Part 26: Stiffness. European Committee for Standardization, Brussels. 
Engelsen, C.J., Mehus, J., Pade, C., Sæther, D.H., 2005. Carbon dioxide uptake in demolished and crushed concrete: CO2 uptake during the concrete life cycle. Oslo, Norway: Nordic Innovation Centre. NIC Project No. 03018, Project report 395-2005.

Gajda, J., 2001. Absorption of atmospheric carbon dioxide by Portland cement concrete (revised in 2006). Skokie, IL: Portland Cement Association. PCA R\&D Serial No. 2255a.

Heywood, J.B., 1988. Internal combustion engine fundamentals. McGraw-Hill, New York.

Huang, Y., Bird, R., Bell, M., 2009a. A comparative study of the emissions by road maintenance works and the disrupted traffic using life cycle assessment and micro-simulation. Transportation Research Part D: Transport and Environment 14(3), 197-204.

Huang, Y., Bird, R., Heidrich, O., 2009b. Development of a life cycle assessment tool for construction and maintenance of asphalt pavements. Journal of Cleaner Production 17(2), 283-296.

Hultqvist, B.-A., 2013. Measurement of fuel consumption on asphalt and concrete pavements north of Uppsala. Measurements with light and heavy goods vehicle. VTI (Swedish National Road and Transport Research Institute), Linköping, Sweden.

ISO 14040, 2006. Environmental management - Life cycle assessment - Principles and framework. International Organization for Standardization, Switzerland.

ISO 14044, 2006. Environmental management - Life cycle assessment - Requirements and guidelines. International Organization for Standardization, Switzerland.

Lagerblad, B., 2006. Carbon dioxide uptake during concrete life cycle - state of the art. Stockholm, Sweden: Swedish Cement and Concrete Research Institute, CBI. Nordic Innovation Centre Project Number 03018. 
Marion, A.-M., De Lanève, M., De Grauw, A., 2005. Study of the leaching behaviour of paving concretes: quantification of heavy metal content in leachates issued from tank test using demineralized water. Cement and Concrete Research 35(5), 951957.

Milachowski, C., Stengel, T., Gehlen, C., 2011. Life Cycle Assessment for Road Construction and Use. EUPAVE - European Concrete Paving Association, Brussels.

Noshadravan, A., Wildnauer, M., Gregory, J., Kirchain, R., 2013. Comparative pavement life cycle assessment with parameter uncertainty. Transportation Research Part D: Transport and Environment 25(0), 131-138.

Nunn, M.E., 2004. Development of a more versatile approach to flexible and flexible composite pavement design. Transport Research Laboroatory (TRL) Report 615 Crowthorne, Berkshire, UK.

Pereira, P.A.A., Oliveira, J.R.M., Picado-Santos, L.G., 2004. Mechanical Characterisation of Hot Mix Recycled Materials. International Journal of Pavement Engineering 5(4), 211-220.

Pérez-Martínez, P.J., 2012. Energy consumption and emissions from the road transport in Spain: A conceptual approach. Transport 27(4), 383-396.

Pérez-Martínez, P.J., Miranda, R.M., 2014. Energy consumption and intensity of toll highway transport in Spain. Transportation Research Part D: Transport and Environment 27, 1-5.

Santero, N.J., Masanet, E., Horvath, A., 2011a. Life-cycle assessment of pavements Part II: Filling the research gaps. Resources, Conservation and Recycling 55(910), $810-818$.

Santero, N.J., Masanet, E., Horvath, A., 2011b. Life-cycle assessment of pavements. Part I: Critical review. Resources, Conservation and Recycling 55(9-10), 801809. 
Shell, 1998. BISAR 3.0 - Bltumen Stress Analysis in Roads. User Manual. Shell International Oil Products BV. The Hague.

Silva, H.M.R.D., Machado, A.V., Oliveira, J.R.M., Costa, L.M.B., 2011. Waste Polymers Recycling In High Performance Asphalt Mixtures, 1st International Conference WASTES: Solutions, Treatments and Opportunities. CVR, Guimarães, Portugal, pp. 17-22.

Stripple, H., 2001. Life cycle assessment of road: a pilot study for inventory analysis. $2^{\mathrm{a}}$ ed., Gothenburg, Sweden: Swedish National Road Administration, IVL B 1210 E.

Taylor, G., Patten, J., 2006. Effects of Pavement Structure on Vehicle Fuel Consumption - Phase III. Report Number CSTT-HVC-TR068, National Research Council Canada, Ottawa, Canada.

Vidal, R., Moliner, E., Martínez, G., Rubio, M.C., 2013. Life cycle assessment of hot mix asphalt and zeolite-based warm mix asphalt with reclaimed asphalt pavement. Resources, Conservation and Recycling 74(0), 101-114.

Wang, T., Lee, I.-S., Kendall, A., Harvey, J., Lee, E.-B., Kim, C., 2012. Life cycle energy consumption and GHG emission from pavement rehabilitation with different rolling resistance. Journal of Cleaner Production 33(0), 86-96.

Wathne, L., 2010. Sustainability Oppurtunities With Pavements: Are We Focusing on the Right Stuff?, International Conference on Sustainable Concrete Pavements: Practices, Challenges, and Directions, Sacramento, California, USA.

WCED, 1987. Our Common Future. Report of the World Comission on Environment and Development. United Nations. Oslo.

Woodside, A., Woodward, D., McErlean, P., 2003. Rolling Resistance of Surface Materials Affected by Surface Type, Tyre Load and Inflation Pressure, MAIREPAV'03 - Maintenance and Rehabilitation of Pavements and Technological Control - International Symposium, Guimarães, Portugal. 